\title{
Room-temperature ferromagnetism in the mixtures of the $\mathrm{TiO}_{2}$ and $\mathrm{Co}_{3} \mathrm{O}_{4}$ powders
}

\author{
A. Serrano, ${ }^{1}$ E. Fernandez Pinel, ${ }^{2}$ A. Quesada, ${ }^{2,3}$ I. Lorite,${ }^{4}$ M. Plaza, ${ }^{1}$ L. Pérez, ${ }^{1}$ F. Jiménez-Villacorta, ${ }^{3,5}$ J. de la Venta, \\ M. S. Martín-González, ${ }^{6}$ J. L. Costa-Krämer, ${ }^{6}$ J. F. Fernandez, ${ }^{4}$ J. Llopis, ${ }^{1}$ and M. A. García ${ }^{1,4, *}$ \\ ${ }^{1}$ Dpto. Física de Materiales, Universidad Complutense de Madrid, 28040 Madrid, Spain \\ ${ }^{2}$ Instituto de Magnetismo Aplicado, UCM, Las Rozas, 28230 Madrid, Spain \\ ${ }^{3}$ Instituto de Ciencia de Materiales de Madrid, CSIC, 28049 Madrid, Spain \\ ${ }^{4}$ Instituto de Cerámica y Vidrio, CSIC, 28049 Madrid, Spain \\ ${ }^{5}$ SpLine, Spanish CRG Beamline at the ESRF, 38043 Grenoble, France \\ ${ }^{6}$ Instituto de Microelectrónica de Madrid, CSIC, Tres Cantos, 28760 Madrid, Spain
}

(Received 11 December 2008; published 3 April 2009)

\begin{abstract}
We report here the observation of ferromagnetism (FM) at $300 \mathrm{~K}$ in mixtures of $\mathrm{TiO}_{2}$ and $\mathrm{Co}_{3} \mathrm{O}_{4}$ powders despite the antiferromagnetic and diamagnetic characters of both oxides, respectively. The ferromagnetic behavior is found in the early stages of reaction and only for $\mathrm{TiO}_{2}$ in anatase structure; no $\mathrm{FM}$ is found for identical samples prepared with rutile- $\mathrm{TiO}_{2}$. Optical spectroscopy and x-ray absorption spectra confirm a surface reduction of octahedral $\mathrm{Co}^{+3} \rightarrow \mathrm{Co}^{+2}$ in the mixtures which is in the origin of the observed magnetism.
\end{abstract}

DOI: 10.1103/PhysRevB.79.144405

PACS number(s): 75.70.-i, 75.30.Et, 75.50.Gg, 78.40.-q

\section{INTRODUCTION}

The appearance and control of magnetism in traditionally nonmagnetic oxides are nowadays some of the most active and pursued goals of material physics. ${ }^{1}$ In the last years, research has been focused mainly on oxides doped with magnetic ions (the so-called diluted magnetic semiconductors). Recent results ${ }^{2-5}$ indicate that the appearance of magnetism in these oxides (mainly $\mathrm{ZnO}$ and $\mathrm{TiO}_{2}$ ) is related to the presence of defects and surface/interface effects ${ }^{6,7}$ but the origin of most of the experimental results is still unclear. ${ }^{8}$ Actually, results are hardly reproducible and findings from different groups are commonly contradictory. Understanding this lack of reproducibility is probably one of the main challenges to determine the origin of this magnetism.

A common feature of all the experimental observations of this magnetism is that signals are very weak, suggesting that only few atoms are involved in the magnetic response. Thus, it has been proposed that the emerging magnetism in oxides corresponds to surface/interface magnetism. ${ }^{9-11}$

It is really tough understanding the origin of this magnetism based only on magnetic measurements since signals are very weak and effects from the rest of the material as impurities could mask the signals coming from interfaces. In this framework, correlating the magnetic properties with other measurements, sensitive to the electronic structure, can help to clarify this magnetism. This is the case of optical measurements as the energy of photons involved in the processes allows discrimination between different processes produced in different atoms. Furthermore, optical properties are particularly sensitive to surfaces as the broken symmetry of the surface induces new electronic levels (surface states) so that they can be especially useful for the investigation of surface effects.

In this work we study the magnetic properties of $\mathrm{TiO}_{2}$ and $\mathrm{Co}_{3} \mathrm{O}_{4}$. Both oxides are mixed in powder form and thermal treated to promote their interaction. Optical and $\mathrm{x}$-ray absorption measurements are used to identify the origin of the observed room-temperature magnetism. The difficulties to reproduce experiments in this kind of materials are also addressed.

\section{EXPERIMENTAL}

Samples were prepared by mixing powders of $\mathrm{TiO}_{2}$ in anatase $\left(A-\mathrm{TiO}_{2}\right)$ and rutile structure $\left(R-\mathrm{TiO}_{2}\right)$ with 1 and 5 wt $\% \mathrm{Co}_{3} \mathrm{O}_{4}$. Analytical grade powders were selected with average particles size in the submicronic range, typically $0.3-0.4 \mu \mathrm{m}$ (see Fig. 1). Pure powders were tested in order to ensure that no ferromagnetic contributions were present. $\mathrm{TiO}_{2}$ powder showed diamagnetic behavior and $\mathrm{Co}_{3} \mathrm{O}_{4}$ paramagnetic one. When subtracting the paramagnetic behavior, some $\mathrm{Co}_{3} \mathrm{O}_{4}$ samples exhibited a weak ferromagneticlike contribution with magnetization below $5 \cdot 10^{-4} \mathrm{emu} / \mathrm{g}$ that disappeared after annealing at $400{ }^{\circ} \mathrm{C} .{ }^{11}$ This residual magnetization due to trace impurities was taking into account and adequately subtracted from the magnetic measurement of mixtures. Any powder with higher ferromagneticlike behavior was considered as contaminated and completely discarded. Initially, the powders were mixed and milled in an attrition mill with zirconia balls for $15 \mathrm{~min}$, and subsequently they were thermally treated in air for $12 \mathrm{~h}$ at different temperatures between 500 and $900{ }^{\circ} \mathrm{C}$. Selected raw materials were also processed following the same procedure to verify experimental conditions. Three different sets of samples were independently prepared at different laboratories (corresponding to authors'affiliations 1,2, and 3). Processing was

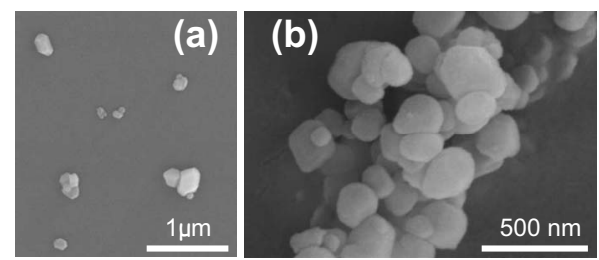

FIG. 1. Scanning electron microscopy (SEM) images from (a) initial $\mathrm{Co}_{3} \mathrm{O}_{4}$ powder. (b) $99 \% A-\mathrm{TiO}_{2}-1 \% \mathrm{Co}_{3} \mathrm{O}_{4}$ sample milled. 

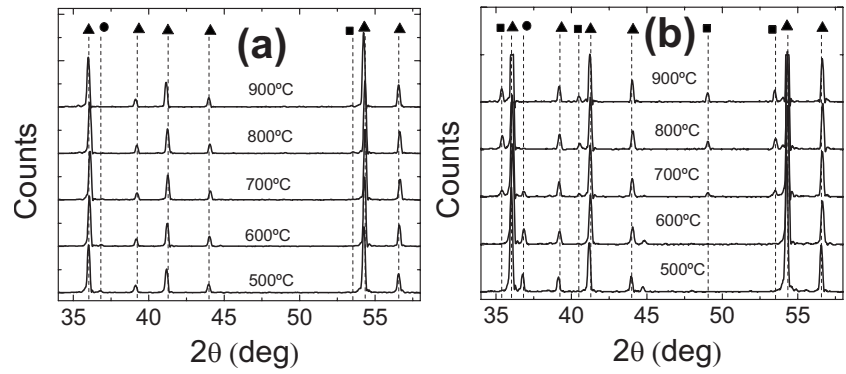

FIG. 2. XRD patterns from $R-\mathrm{TiO}_{2}$ with (a) $1 \mathrm{~mol} \%$ of $\mathrm{Co}_{3} \mathrm{O}_{4}$ and (a) $5 \mathrm{~mol} \%$ of $\mathrm{Co}_{3} \mathrm{O}_{4}$. Symbols stand for $(\mathbf{\Delta}) \mathrm{TiO}_{2}$ rutile, ( $\mathrm{Co}_{3} \mathrm{O}_{4}$, and (ם) $\mathrm{CoTiO}_{3}$.

managed without using any kind of metallic tools to prevent contamination

The structural analysis of the samples was carried out with a Siemens D5000 x-ray diffractometer (XRD) using a monochromatic $\mathrm{Cu} \mathrm{K}$ line and operating at $40 \mathrm{kV}$ and 40 $\mathrm{mA}$. Magnetic characterization was performed in three different vibrating sample magnetometers (VSMs): VSM LDJ instruments, Quantum Design physical properties measurement system (PPMS)-VSM, and VSM Lakeshore 7304. For the magnetic measurements, all possible sources of experimental errors described in Ref. 12 were taken into account. Optical absorption was measured with a Shimadzu 3101 spectrophotometer attached with an integrating sphere. X-ray absorption spectroscopy (XAS) was performed at beamline BM25 (SpLine) in the European Synchrotron Radiation Facility at Grenoble.

\section{RESULTS AND DISCUSSION}

Figure 2 presents XRD measurements for the samples prepared using $R-\mathrm{TiO}_{2}$. Up to annealing temperatures of $600{ }^{\circ} \mathrm{C}$ only the initial $R-\mathrm{TiO}_{2}$ and $\mathrm{Co}_{3} \mathrm{O}_{4}$ phases are observed in the XRD patterns. After annealing at $700{ }^{\circ} \mathrm{C}$, some peaks from $\mathrm{CoTiO}_{3}$ appear for the samples with $5 \% \mathrm{Co}_{3} \mathrm{O}_{4}$, coexisting with the initial phases. These data confirm that the reaction between both phases has started at this temperature. The peaks are scarcely identified for the samples with $1 \%$ $\mathrm{Co}_{3} \mathrm{O}_{4}$. This is quite reasonable since the amount of $\mathrm{CoTiO}_{3}$ that can be formed is limited mainly by the concentration of $\mathrm{Co}_{3} \mathrm{O}_{4}$ in the sample. Thus, the differences between both samples seem more related to the detection limit of the experimental setup than to structural differences. As the temperature increases over $700{ }^{\circ} \mathrm{C}$, the peaks from $\mathrm{CoTiO}_{3}$ also do, while the $\mathrm{Co}_{3} \mathrm{O}_{4}$ ones decrease, disappearing at $800{ }^{\circ} \mathrm{C}$. At this temperature, all the $\mathrm{Co}_{3} \mathrm{O}_{4}$ in the sample have reacted with the $\mathrm{TiO}_{2}$ forming $\mathrm{CoTiO}_{3}$. Due to the small fraction of $\mathrm{Co}_{3} \mathrm{O}_{4}$, there is an excess of $\mathrm{TiO}_{2}$ that remains unaltered in the sample at all annealing temperatures, as evidenced in the XRD patterns.

Summarizing, the annealing process induces the interaction between both phases, consisting in the reaction of the $\mathrm{Co}_{3} \mathrm{O}_{4}$ with a small amount of $R-\mathrm{TiO}_{2}$ to form $\mathrm{CoTiO}_{3}$. The reaction starts below $700{ }^{\circ} \mathrm{C}$ and is completed over $800^{\circ}$, when all the $\mathrm{Co}_{3} \mathrm{O}_{4}$ have reacted to form the spinel phase that coexists with the excess of $R-\mathrm{TiO}_{2}$.
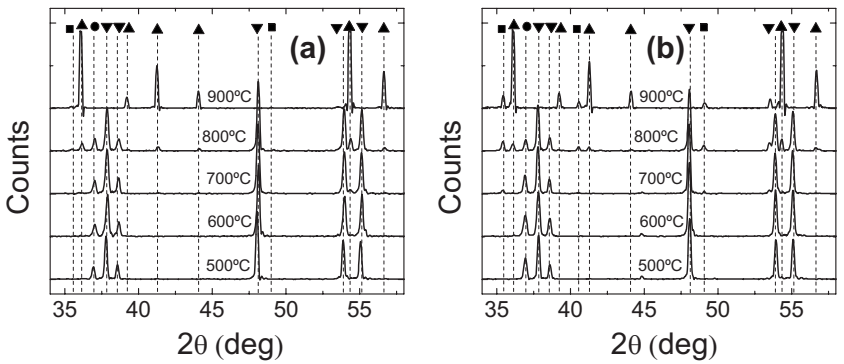

FIG. 3. XRD patterns from $A-\mathrm{TiO}_{2}$ with (a) $1 \mathrm{~mol} \%$ of $\mathrm{Co}_{3} \mathrm{O}_{4}$ and (a) $5 \mathrm{~mol} \%$ of $\mathrm{Co}_{3} \mathrm{O}_{4}$. Symbols stand for $(\boldsymbol{\nabla}) \mathrm{TiO}_{2}$ anatase, $(\boldsymbol{\Delta}) \mathrm{TiO}_{2}$ rutile, $(\bullet) \mathrm{Co}_{3} \mathrm{O}_{4}$, and $(\boldsymbol{\square}) \mathrm{CoTiO}_{3}$.

The XRD patterns from the samples prepared with $A-\mathrm{TiO}_{2}$ are more complicated (Fig. 3). As in the case of $R$ - $\mathrm{TiO}_{2}$, up to $600{ }^{\circ} \mathrm{C}$ only the initial phases are observed in the XRD diffractograms. After annealing at $700{ }^{\circ} \mathrm{C}$ the presence of scarce peaks, ascribed to $\mathrm{CoTiO}_{3}$, coexisting with the initial phases, indicates a partial reaction. Simultaneously, peaks from $R-\mathrm{TiO}_{2}$ are shown, confirming that the transformation of $A-\mathrm{TiO}_{2} \rightarrow R-\mathrm{TiO}_{2}$ has started at this temperature. The presence of $\mathrm{CoTiO}_{3}$ increases with the temperature of the thermal treatment, while the transformation of $A-\mathrm{TiO}_{2}$ $\rightarrow R-\mathrm{TiO}_{2}$ is completed at $900{ }^{\circ} \mathrm{C}$. At this temperature, only $R-\mathrm{TiO}_{2}$ and $\mathrm{CoTiO}_{3}$ are present in the sample (as for the samples prepared with $R-\mathrm{TiO}_{2}$ ).

Therefore, for these samples, the annealing produces two simultaneous processes: the reaction of $\mathrm{TiO}_{2}$ with $\mathrm{Co}_{3} \mathrm{O}_{4}$ (similar to that produced in samples with $R-\mathrm{TiO}_{2}$ ) and the transformation $A-\mathrm{TiO}_{2} \rightarrow R-\mathrm{TiO}_{2}$.

Magnetic characterization of the samples is presented in Fig. 4. The overall behavior is paramagnetic with susceptibility decreasing up to annealing temperature of $500{ }^{\circ} \mathrm{C}$ and increasing for higher temperatures. According to XRD diffractograms, the increase in magnetic susceptibility is due to
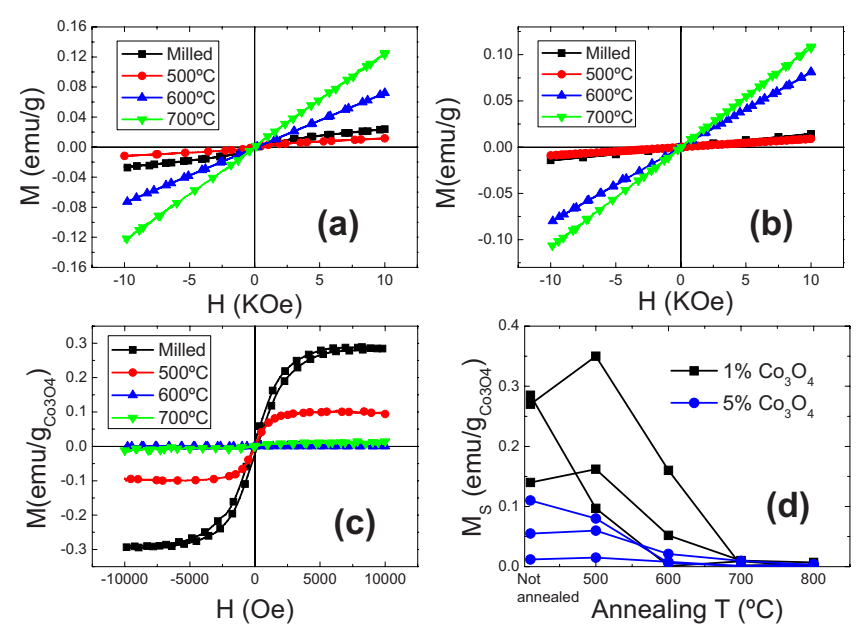

FIG. 4. (Color online) Magnetization curves for $99 \% \mathrm{TiO}_{2}-1 \% \mathrm{Co}_{3} \mathrm{O}_{4}$ samples annealed at different temperatures for (a) $A-\mathrm{TiO}_{2}$ and (b) $R-\mathrm{TiO}_{2}$. (c) Curves for the samples with $\mathrm{TiO}_{2}$ in anatase structure after subtraction of a paramagnetic (linear) component. (d) Saturation magnetization of the ferromagnetic component for the samples prepared with $A-\mathrm{TiO}_{2}$ with 1 and 5 wt $\%$ of $\mathrm{Co}_{3} \mathrm{O}_{4}$. 
the reaction of the $\mathrm{Co}_{3} \mathrm{O}_{4}$ with the $\mathrm{TiO}_{2}$ to form $\mathrm{CoTiO}_{3}$ that has larger magnetic susceptibility than $\mathrm{Co}_{3} \mathrm{O}_{4} \cdot{ }^{13,14}$ Differences in the value of magnetic susceptibility for rutile and anatase samples can be explained in terms of the different kinetic of the reaction with $\mathrm{Co}_{3} \mathrm{O}_{4}$. Rutile exhibits a more closed structure than anatase, ${ }^{15}$ so the reaction with $\mathrm{Co}_{3} \mathrm{O}_{4}$ is slower than for anatase, which exhibits a more opened structure and is therefore more reactive. Hence, for a fixed temperature, the degree of transformation is smaller for rutile, and the magnetic susceptibility decreases accordingly (as the transformed $\mathrm{CoTiO}_{3}$ exhibits larger susceptibility).

Despite the diamagnetic character of $\mathrm{TiO}_{2}$ and the antiferromagnetic behavior of $\mathrm{Co}_{3} \mathrm{O}_{4}$ and $\mathrm{CoTiO}_{3}$ (with Néel temperatures of 42 and $37 \mathrm{~K}$, respectively), we found a ferromagnetic contribution at room temperature for the samples with $\mathrm{Co}_{3} \mathrm{O}_{4}$ and $A-\mathrm{TiO}_{2}$ milled and after annealing at low 500 and $600{ }^{\circ} \mathrm{C}$ [Fig. 4(c)]; this contribution is not observed in the $R-\mathrm{TiO}_{2}$ samples in all range of temperatures.

The experiment was repeated three different times at different laboratories, using oxides from different suppliers with similar specifications and different experimental setups. While the quantitative results are different [see Fig. 4(d)], in all three cases we found the same effect: ferromagnetism at room temperature is only observed when using $A-\mathrm{TiO}_{2}$ structure and after annealing at low temperature (below $700{ }^{\circ} \mathrm{C}$ ). Quantitative differences appear in the maximum value of $M_{S}$, which ranges from $3.6 \cdot 10^{-1}$ to $1 \cdot 10^{-1} \mathrm{emu} / \mathrm{g}_{\mathrm{Co}_{3} \mathrm{O}_{4}}$. The highest $M_{S}$ in the presented data appears after milling, while for the other two sets it is found after $500{ }^{\circ} \mathrm{C}$ of annealing [Fig. 4(d)]. For the samples with $5 \% \mathrm{Co}_{3} \mathrm{O}_{4}$, the effect also exists, although the value of $M_{S}$ is fairly smaller than for those samples with $1 \% \mathrm{Co}_{3} \mathrm{O}_{4}$. The paramagnetic component, on the other hand, is found to be basically the same for the samples annealed at the same temperature but prepared at different laboratories.

The appearance of room-temperature magnetism in $\mathrm{TiO}_{2}$-based materials containing cobalt only for the anatase structure is in agreement with most of the experimental results published for the Ti-O-Co system ${ }^{16-20}$ while scarce experiments are reported for $R-\mathrm{TiO}_{2}{ }^{21}$

However, the appearance of magnetism just after a short milling is surprising as no diffusion or strong interaction is expected at this stage. Such behavior indicates some interaction between $\mathrm{TiO}_{2}$ and $\mathrm{Co}_{3} \mathrm{O}_{4}$ just after milling. The weak ferromagnetic signal suggests that only a small part of the material exhibits ferromagnetic behavior, which is consistent with the nonferromagnetic behavior of $\mathrm{TiO}_{2}$ and $\mathrm{Co}_{3} \mathrm{O}_{4}$, the only phases observed by XRD in the ferromagnetic samples. The magnetic signal could then arise at the interfaces between both oxides, which are modified in the first stages of the reaction and are not detected by XRD since they represent a very small fraction of the whole material.

In order to confirm that this early interaction leads to a modification of the electronic configuration of the oxides, we performed optical measurements. Optical reflection spectra for the samples with $5 \% \mathrm{Co}_{3} \mathrm{O}_{4}$ after the different thermal treatments are presented in Fig. 5. Results for the samples containing $1 \% \mathrm{Co}_{3} \mathrm{O}_{4}$ were similar (although the features arising from the $\mathrm{Co}_{3} \mathrm{O}_{4}$ are not so clearly resolved).

Both $A-\mathrm{TiO}_{2}$ and $R-\mathrm{TiO}_{2}$ samples exhibit slight shifts in the edge after milling. This process acts as a very efficiency
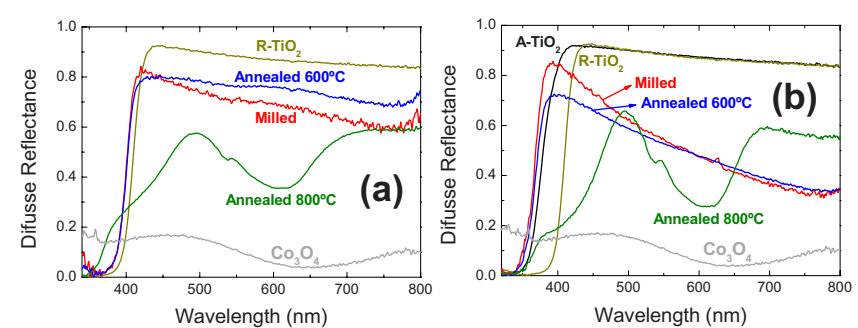

FIG. 5. (Color online) Diffusion reflectance spectra for the samples containing $5 \% \mathrm{Co}_{3} \mathrm{O}_{4}$ prepared with (a) rutile and (b) anatase $\mathrm{TiO}_{2}$. Spectra from $R-\mathrm{TiO}_{2}, A-\mathrm{TiO}_{2}$, and $\mathrm{Co}_{3} \mathrm{O}_{4}$ are also presented for comparison purposes.

homogenizer procedure that favors the appearance of $\mathrm{Co}_{3} \mathrm{O}_{4}-\mathrm{TiO}_{2}$ particles contacts during the drying step because of van der Waals forces (Fig. 1). It is well known that the optical processes are very sensitive to surface effects, which may modify electronic levels or introduce new ones that can account for the observed shifts.

The samples with ferromagnetic behavior (those prepared with anatase and mixed and low-temperature annealed) exhibit a maximum in the reflectance at the edge $(390-400 \mathrm{~nm})$ which is absent in all the other samples. This maximum is the combination of the $\mathrm{TiO}_{2}$ edge and a broad absorption band in the green-red par of the spectrum. Actually, the magnetic samples are the only ones exhibiting a blue coloration. ${ }^{22}$ It is particularly noteworthy that the equivalent samples prepared with $R-\mathrm{TiO}_{2}$ show gray color.

Blue color is characteristic of compounds containing $\mathrm{Co}^{+2}$ atoms in octahedral positions. ${ }^{23}$ However, $\mathrm{Co}_{3} \mathrm{O}_{4}$ has spinel structure with the $\mathrm{Co}^{+2}$ ions in tetrahedral $(T)$ positions and the $\mathrm{Co}^{+3}$ ions in octahedral $(O)$ ones. ${ }^{14}$ Thus, the blue color could be explained by a reduction of the $\mathrm{Co}^{+3}$ ions in $O$ positions to $\mathrm{Co}^{+2}$ due to the interaction with the $A-\mathrm{TiO}_{2}$. In order to check this hypothesis, we performed x-ray absorption spectroscopy in the Co K edge.

Figure 6 presents the XAS spectra at the Co $\mathrm{K}$ edge of pure $\mathrm{Co}_{3} \mathrm{O}_{4}$ and samples $95 \% \mathrm{TiO}_{2}-5 \% \mathrm{Co}_{3} \mathrm{O}_{4}$ samples prepared with $A-\mathrm{TiO}_{2}$ and $R-\mathrm{TiO}_{2}$.

The spectra [Fig. 6(a)] are very similar as expected since interaction between both oxides is limited to a narrow sur-
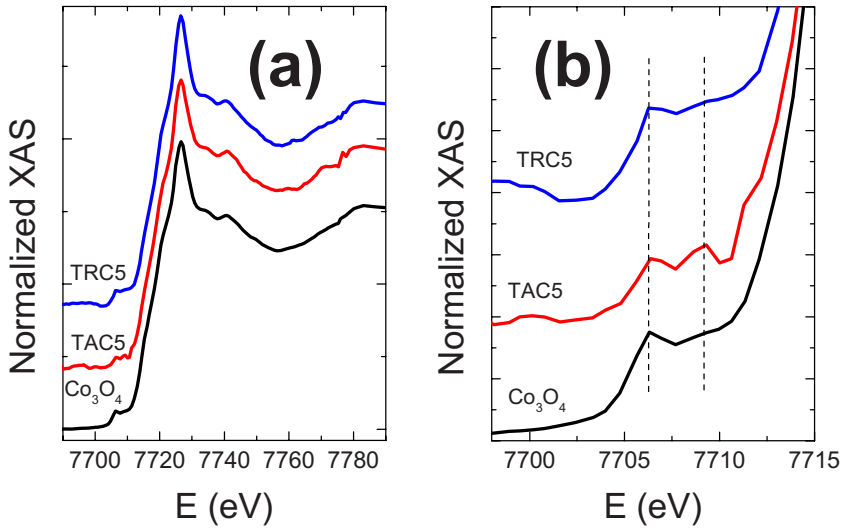

FIG. 6. (Color online) (a) XANES spectra at the Co K edge for pure $\mathrm{Co}_{3} \mathrm{O}_{4}$ and samples $95 \% \mathrm{TiO}_{2}-5 \% \mathrm{Co}_{3} \mathrm{O}_{4}$ samples prepared with $A-\mathrm{TiO}_{2}$ (TAC5) and $R-\mathrm{TiO}_{2}$ (TAC5). (b) Detail of the pre-edge region. 
face region. No clear shift of the edge is found. However, the detail of the prepeak shown in Fig. 6(b) evidences some changes. The feature in the $\mathrm{Co}_{3} \mathrm{O}_{4}$ spectra at about $7707 \mathrm{eV}$ corresponds to a bound $1 s-3 d$ transition of tetrahedrally coordinated metal ions ${ }^{24,25}$ which is forbidden for positions with a center of inversion as octahedral ones. Therefore, for $\mathrm{Co}_{3} \mathrm{O}_{4}$, this peak is characteristic of $\mathrm{Co}^{+2}$ in tetrahedral positions. The prepeak feature is very similar for the sample prepared with $R-\mathrm{TiO}_{2}$ confirming the weak interaction between $\mathrm{TiO}_{2}$ and $\mathrm{Co}_{3} \mathrm{O}_{4}$ after milling in this sample. On the contrary, for the sample with $A-\mathrm{TiO}_{2}$, the peak is reduced and splits into two, corroborating the modification of the Co electronic structure. The appearance of a peak at about $7709 \mathrm{eV}$ has been ascribed to Co in octahedral position with a lower oxidation state, ${ }^{26}$ which agrees with results of the optical spectroscopy and confirms the surface $\mathrm{Co}^{+3} \rightarrow \mathrm{Co}^{+2}$ reduction in these sample. In our case, the vicinity of $\mathrm{Ti}$ atoms may break the octahedral symmetry inducing a distortion that can allow the presence of the prepeak. Calculations (not presented here) of the $\mathrm{x}$-ray appearance near-edge structure (XANES) spectrum for a $\mathrm{TiO}_{2} / \mathrm{Co}_{3} \mathrm{O}_{4}$ interface with $\mathrm{Co}^{+2}$ in octahedral positions showed a double prepeak at the same positions than those observed experimentally. A similar behavior was observed for the samples annealed at 500 and $600{ }^{\circ} \mathrm{C}$ that exhibit also ferromagnetic signals. ${ }^{22}$ These results confirm that the early interaction of the $\mathrm{Co}_{3} \mathrm{O}_{4}$ with the $A-\mathrm{TiO}_{2}$ induces the reduction of the $\mathrm{Co}^{+3}$ in $O$ positions to $\mathrm{Co}^{+2}$, while this effect is not observed in the samples prepared with $R-\mathrm{TiO}_{2}$. Concerning the origin of the interaction, an electrochemical solid state reaction taking place at the oxides surface has been proposed. ${ }^{27}$

Optical and XAS spectroscopy studies point on the Co reduction as the origin of the ferromagnetic signal. As indicated above, $\mathrm{Co}_{3} \mathrm{O}_{4}$ presents the spinel structure as most of the ferrimagnetic materials, such as $\mathrm{Fe}_{3} \mathrm{O}_{4}$ or $\mathrm{NiCo}_{2} \mathrm{O}_{4}$, with the $\mathrm{Co}^{+2}$ ions in $T$ positions and the $\mathrm{Co}^{+3}$ ions in $O$ ones. ${ }^{14}$ For this structure, the predominant interaction is the antiferromagnetic superexchange between $T$ and $O$ positions, while interactions $T-T$ and $O-O$ are also antiferromagnetic but much weaker than the $T-O$ one. Consequently, there are two magnetic sublattices corresponding to $T$ and $O$ positions with antiparallel orientation. Therefore, these ferrite-type spinels exhibit ferrimagnetic behavior with high order temperature $\left(T_{C}=858 \mathrm{~K}\right.$ for $\mathrm{Fe}_{3} \mathrm{O}_{4}$, or $673 \mathrm{~K}$ for $\left.\mathrm{NiCo}_{2} \mathrm{O}_{4}\right)$. However, for $\mathrm{Co}_{3} \mathrm{O}_{4}, \mathrm{Co}^{+3}$ ions in $O$ positions present no magnetic moment due to the large splitting of the $3 d$ orbital in this symmetry. ${ }^{14}$ Hence, in $\mathrm{Co}_{3} \mathrm{O}_{4}$ only $\mathrm{Co}^{+2}$ in $T$ position holds a magnetic moment and the $T-T$ weak antiferromagnetic interaction is the dominant one, so the system present antiferromagnetic behavior with a much lower order temperature of $T_{N}=42 \mathrm{~K}$. However, for $\mathrm{Co}^{+2}$ atoms in an octahedral field, the orbital splitting is quite small and $\mathrm{a} \mathrm{Co}^{+2}$ atom in this symmetry should hold a magnetic moment. ${ }^{14}$ For a region of the crystal where $\mathrm{Co}^{+3}$ in $O$ positions are reduced to $\mathrm{Co}^{+2}$ there should be magnetic moments in both $O$ and $T$ positions with partially filled $t_{2 g}$ orbitals. In this situation, the $T-O$ antiferromagnetic interaction would be the dominant one and the system should present a behavior similar to that of $\mathrm{Fe}_{3} \mathrm{O}_{4}$, that is, ferrimagnetism with high order temperature (due to the strong interaction $T-O)$. Consequently, the observed weak ferromagnetic signal can be explained by the reduction of $\mathrm{Co}^{+3}$ in $O$ positions to $\mathrm{Co}^{+2}$ demonstrated by XANES and optical spectra, and no new magnetic ordering mechanisms are required to account for it. However, the effect in $\mathrm{Co}_{3} \mathrm{O}_{4}$ will be restricted to very small surface regions; the spinel structure of $\mathrm{Co}_{3} \mathrm{O}_{4}$ is unstable if a large fraction of $\mathrm{Co}^{+3}$ is reduced to $\mathrm{Co}^{+2}$ promoting the transformation to $\mathrm{CoO}$ which is antiferromagnetic. Thus, it is not possible to obtain a bulk ferrimagnetic material nor a material with uniform magnetic properties based on this effect.

Surface is the most sensitive part of the materials to any kind of treatment or interaction. Thus, nominally identical oxides from different suppliers can present identical bulk properties but fairly different surfaces. Properties depending on the surface and its reactivity in the first stages can be completely different, as we found for the three sets of samples analyzed here. This experimental fact could account for the discrepancies in results from different groups that use powder nominally identical with the same bulk structure but different surfaces due to different origin. This idea is also supported by recent results ${ }^{28}$ that show that a precalcination (just at $400{ }^{\circ} \mathrm{C}$ ) of $\mathrm{ZnO}$ alters its surface electronic structure and consequently its reactivity.

\section{CONCLUSIONS}

In summary, we have demonstrated that a weak interaction between Anatase- $\mathrm{TiO}_{2}$ and $\mathrm{Co}_{3} \mathrm{O}_{4}$ surface induces a surface reduction of $\mathrm{Co}^{+3}$ atoms in octahedral positions to $\mathrm{Co}^{+2}$ generating a weak ferromagnetic signal at room temperature. This magnetic signal can be explained as due to superexchange interactions (as the situation is similar to that in $\mathrm{Fe}_{3} \mathrm{O}_{4}$ ) and no new magnetic ordering mechanisms are required to account for it. This demonstrates the possibility of observing weak ferromagnetic signals in samples containing $\mathrm{Ti}, \mathrm{O}$, and $\mathrm{Co}$ that must be considered when studying the magnetic properties of $\mathrm{Co}: \mathrm{TiO}_{2}$ diluted magnetic semiconductors and similar materials.

\section{ACKNOWLEDGMENTS}

This work was supported by the Spanish Council for Scientific Research through the CSIC Projects No. 200650F0122 and No. 2007-50I015 and Spanish Ministry of Science and Education through the Projects No. MAT200766845-C02-01 and No. FIS-2008-06249. We acknowledge the European Synchrotron Radiation Facility for provision of synchrotron radiation facilities, and we would like to thank the SpLine CRG Beamline staff for assistance during x-ray absorption experiments. 
*Corresponding author; ma.garcia@ fis.ucm.es

${ }^{1}$ K. Ando, Science 312, 1883 (2006); H. Ohno, ibid. 281, 951 (1998).

${ }^{2}$ K. R. Kittilstved, N. S. Norberg, and D. R. Gamelin, Phys. Rev. Lett. 94, 147209 (2005).

${ }^{3}$ J. M. D. Coey, M. Venkatesan, and C. B. Fitzgerald, Nature Mater. 4, 173 (2005).

${ }^{4}$ K. R. Kittilstved and D. R. Gamelin, J. Am. Chem. Soc. 127, 5292 (2005)

${ }^{5}$ K. R. Kittilstved, W. K. Liu, and D. R. Gamelin, Nature Mater. 5, 291 (2006).

${ }^{6}$ A. Brinkman, M. Huijben, M. van Zalk, J. Huijben, U. Zeitler, J. C. Maan, W. G. van der Wiel, G. Rijnders, D. H. A. Blank, and H. Hilgenkamp, Nature Mater. 6, 493 (2007).

${ }^{7}$ M. S. Martín-González, J. F. Fernández, F. Rubio-Marcos, I. Lorite, J. L. Costa-Krämer, A. Quesada, M. A. Bañares, and J. L. G. Fierro, J. Appl. Phys. 103, 083905 (2008).

${ }^{8}$ J. M. D. Coey and S. A. Chambers, MRS Bull. 33, 1053 (2008).

${ }^{9}$ J. L. Costa-Krämer, F. Briones, J. F. Fernandez, A. C. Caballero, M. Villegas, M. Diaz, M. A. García, and A. Hernando, Nanotechnology 16, 214 (2005).

${ }^{10}$ M. A. Garcia, M. L. Ruiz-Gonzalez, A. Quesada, J. L. CostaKramer, J. F. Fernandez, S. J. Khatib, A. Wennberg, A. C. Caballero, M. S. Martin-Gonzalez, M. Villegas, F. Briones, J. M. Gonzalez-Calbet, and A. Hernando, Phys. Rev. Lett. 94, 217206 (2005).

${ }^{11}$ A. Quesada, M. A. García, M. Andrés, A. Hernando, J. F. Fernández, A. C. Caballero, M. S. Martín-González, and F. Briones, J. Appl. Phys. 100, 113909 (2006).

${ }^{12}$ M. A. Garcia, E. Fernandez Pinel, J. de la Venta, A. Quesada, V. Bouzas, J. F. Fernández, J. J. Romero, M. S. Martín González, and J. L. Costa-Krämer, J. Appl. Phys. 105, 013925 (2009).

${ }^{13}$ J. S. Stickler, S. Kern, A. Wold, and G. S. Heller, Phys. Rev. 164, 765 (1967).

${ }^{14}$ W. L. Roth, J. Phys. Chem. Solids 25, 1 (1964).
${ }^{15}$ S. R. Yoganarasimhan and C. N. R. Rao, Trans. Faraday Soc. 58 1579 (1962).

${ }^{16}$ Y. Matsumoto, M. Murakami, T. Shono, T. Hasegawa, T. Fukumura, M. Kawasaki, P. Ahmet, T. Chikyow, S. Koshihara, and H. Koinuma, Science 291, 854 (2001).

${ }^{17}$ S. R. Shinde, S. B. Ogale, S. Das Sarma, J. R. Simpson, H. D. Drew, S. E. Lofland, C. Lanci, J. P. Buban, N. D. Browning, V. N. Kulkarni, J. Higgins, R. P. Sharma, R. L. Greene, and T. Venkatesan, Phys. Rev. B 67, 115211 (2003).

${ }^{18}$ J. S. Higgins, S. R. Shinde, S. B. Ogale, T. Venkatesan, and R. L. Greene, Phys. Rev. B 69, 073201 (2004).

${ }^{19}$ K. A. Griffin, A. B. Pakhomov, C. M. Wang, S. M. Heald, and K. M. Krishnan, Phys. Rev. Lett. 94, 157204 (2005).

${ }^{20}$ H. Toyosaki, T. Fukumura, Y. Yamada, K. Nakajima, T. Chikyow, T. Hasegawa, H. Koinuma and M. Kawasaki, Nature Mater. 3, 221 (2004).

${ }^{21}$ Y. Matsumoto, R. Takahashi, M. Murakami, T. Koida, X. Fan, T. Hasegawa, T. Fukumura, M. Kawasaki, S. Koshihara, and H. Koinuma, Jpn. J. Appl. Phys., Part 2 40, L1204 (2001).

${ }^{22}$ See EPAPS Document No. E-PRBMDO-79-085910 for a photograph showing the samples coloration and the XANES spectra of the samples annealed at 500 and $600{ }^{\circ} \mathrm{C}$. For more information on EPAPS, see http://www.aip.org/pubservs/epaps.html.

${ }^{23}$ D. Sutton, Electronic Spectra of Transition Metal Complexes (McGraw-Hill, Berkshire, England, 1975).

${ }^{24}$ M. F. F. F. Lelis, A. O. Porto, C. M. Gonçalvs, and J. D. Fabris, J. Magn. Magn. Mater. 278, 263 (2004).

${ }^{25}$ T. Jiang and D. E. Ellis, J. Mater. Res. 11, 2242 (1996).

${ }^{26}$ J. Jason, A. E. C. Palmqvist, E. Fridell, M. Skoglundh, L. Österlund, P. Thormählen, and V. Langer, J. Catal. 211, 387 (2002).

${ }^{27}$ M. S. Martín-González (private communication).

${ }^{28}$ F. Rubio-Marcos, A. Quesada, M. A. García, M. A. Bañares, J. L. G. Fierro, M. S. Martín-Gonzalez, J. L. Costa-Krämer, and J. F. Fernández, J. Solid State Chem. (to be published). 